\title{
Doing the MATH: is the mouse a good model for fly development?
}

\author{
Bassem A. Hassan ${ }^{1,3}$ and Hugo J. Bellen ${ }^{1-3}$ \\ ${ }^{1}$ Department of Molecular and Human Genetics, the Howard Hughes Medical Institute, and ${ }^{2}$ Program in Developmental \\ Biology, Baylor College of Medicine, Houston, Texas 77030 USA
}

Members of the superfamily of basic helix-loop-helix (bHLH) proteins have been shown to play important roles in neurogenesis in many species. Neuronal bHLH proteins can be divided into two families: the AchaeteScute complex (AS-C) related proteins and the Atonalrelated proteins, or ARPs. In this review we discuss the ARPs, focusing on their functional diversity within each organism and contrasting it with the remarkable conservation of some of the functions across species. In reviewing the current data, three themes emerge. First, the sequence of the basic domain is sufficient to delineate the different groups of ARPs. Second, the structural similarities among the three groups of ARPs, namely the Neurogenin group, the NeuroD group, and the ATO group, appear to reflect functional similarities. Finally, the dual functions of Drosophila proneural ARPs in precursor selection and lineage identity specification may have been uncoupled in vertebrates.

\section{Our ignorance of the laws of variation is profound. Charles Darwin}

bHLH transcription factors are known to regulate key aspects of precursor determination and lineage differentiation in a wide variety of tissues and developmental stages in multicellular organisms (Baer 1993; Dias et al. 1994; Jan and Jan 1994; Olson and Klein 1994; Sengupta and Bargman 1996; Sommer et al. 1996; Kageyama et al. 1997; Lee 1997; Fisher and Caudy 1998; Modolell and Campuzano 1998; Chitnis 1999; Guillemot 1999; Malicki et al. 1999; Gradwohl et al. 2000; Liu et al. 2000). The bHLH domain is necessary and, in some cases, sufficient for the function of bHLH proteins (Davis and Weintraub 1992; Ma et al. 1993; Hinz et al. 1994; Chien et al. 1996). bHLH proteins acting in different tissues, such as the myogenic and neural bHLHs, generally belong to distinct families, although some overlap is observed. Within each family, bHLH proteins share significant homology in the bHLH domain, but little homology elsewhere. Structural and biochemical analyses reveal that tissue-specific bHLH proteins form DNA binding

${ }^{3}$ Corresponding authors.

E-MAIL bhassan@bcm.tmc.edu; FAX (713) 798-3694.

E-MAIL hbellen@bcm.tmc.edu; FAX (713) 798-3694. heterodimers with the ubiquitously expressed Daughterless-like proteins and contact the E-box binding site via the basic domain. The HLH motif functions as a dimerization domain (Murre et al. 1989a,b; Blackwell et al. 1990; Cabrera and Alonso 1991; Kerkhoff et al. 1991; Ellenberger et al. 1994; Ma et al. 1994).

\section{The basics of lineage identity}

In this review we define the basic domain as a stretch of 12 amino acids beginning with the arginine residue common to all bHLH proteins. Close examination of the basic domains of different bHLH protein families indicates that they include residues specific to each family (Fig. 1A). For example, all AS-C proteins and their vertebrate homologs have a three amino acid gap (residues 3-5), whereas the ubiquitously expressed protein Daughterless and its vertebrate homologs have an asparagine at position 5 and an isoleucine at position 11 . Therefore, amino acid differences in the basic domain alone may provide a basis for the comparison between distinct families of bHLH proteins.

Do the sequence differences in the basic domain reflect the differences in functional specificity among the bHLH protein families? An early clue to the answer of this question came from studies by Davis and colleagues (Davis et al. 1989, 1990) who showed that the basic domain of the myogenic protein MyoD contained sequences necessary for its myogenic activity. Furthermore, replacement of the MyoD HLH domain by that of Scute had little effect on the myogenic activity of MyoD. In contrast, the replacement of the MyoD basic domain by that of Scute severely reduced the myogenic activity of the hybrid protein, despite its ability to bind DNA in a sequence-specific manner. These data suggested that myogenic lineage information specificity is at least partly encoded by the basic domain.

\section{Making chordotonal organs}

A proneural gene can be defined by two criteria. First, its expression precedes and coincides with the selection of neuronal precursor cells. Second, its function is both necessary and sufficient for the specification and devel- 
A

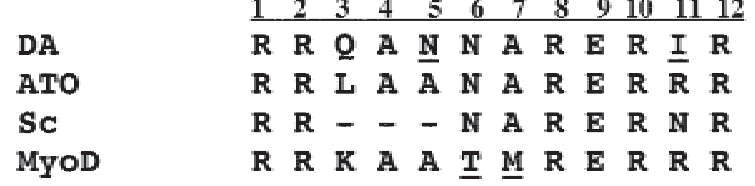

B NGN Group: Biparous/TAP RRMKANDRERNR XNGN1 (a\&b) MNGN1 / MATH4C/MNeurOD3 MNGN2/MATH4a MNGN3/MATH4b

NeuroD Group
DATH23
zNdr1a
zNdr2
XNeuroD
XATH3
MATH2/NEX1
MATH3/Neuro
MNeuroD1/B
MNeuroD2/ND
ATO Group:
LIN-32
ATO
AMOS
CATO
XATH1
XATH5
MATH1
MATH5

Figure 1. The DNA binding basic domain of bHLH proteins contains. (A) Sequence comparison of the basic domains of Atonal, Daughterless, Scute, and MyoD. MyoD and Daughterless have characteristic residues (underlined) which are invariant among their homologs. None of these residues are predicted to make direct contact with DNA. (B) Comparison of the basic domains of the different groups of ARPs. Residues common to all neural bHLHs are shown in red; residues common to all ARPs are shown in blue; residues that characterize each group are shown in green. Conservative substitutions are denoted by a wavy underline; nonconservative substitutions are underlined. In the cases of DATH23, XATH3, MATH2, and MATH3, the nonconservative substitutions are also shown in purple to point out the possibility that these proteins may form related subgroups within the NeuroD group.

opment of a given neuronal lineage in a cell autonomous fashion. Therefore, loss of function of a proneural gene results in the deletion of the lineage it specifies. Conversely, its misexpression produces the given neuronal lineage in ectopic locations /Ghysen and DamblyChaudiere 1989; Campuzano and Modolell 1992; Jan and Jan 1994; Anderson 1995; Hassan and Vaessin 1996; Hinz 1997; Guillemot 1999; Bray 2000). In Drosophila, the $A S-C$ genes were identified as proneural genes encoding bHLH proteins whose functions are critical for central (CNS) and peripheral nervous system (PNS) development
Garcia-Bellido and Santamaria 1978; Garcia-Bellido 1979; Dambly-Chaudiere and Ghysen 1987; Ruiz-Gomez and Modolell 1987; Villares and Cabrera 1987; Ghysen and Dambly-Chaudiere 1989; Skeath and Carroll 1991). The Drosophila PNS contains four types of sensory organs (Jan and Jan 1993): the external mechanosensory and chemosensory organs called external sensory organs (ESOs); the internal stretch receptors called chordotonal organs (CHOs); the olfactory sense organs; and the multidendritic neurons. Early studies identified the AS-C proteins as necessary for the development of some multidendritic neurons and most of the ESOs. However, the $\mathrm{CHOs}$ and some multidendritic neurons were largely unaffected by the loss of the $A S-C$ (Dambly-Chaudiere and Ghysen 1987). In contrast, loss of Daughterless, which forms DNA-binding heterodimers with the AS-C proteins, resulted in the elimination of the entire PNS (Caudy et al. 1988). These data suggested that other proneural bHLH proteins were yet to be identified. In 1993, Jarman and colleagues cloned the atonal gene (ato) and showed that it encodes a bHLH protein (Jarman et al. 1993). ATO is necessary and sufficient for the production of most CHOs, one subset of olfactory sense organs, and some multidendritic neurons (Jarman et al. 1993; Gupta and Rodrigues 1997). Embryos mutant for both ATO and the AS-C retain two subsets of olfactory sense organs and one solitary multidendritic neuron per hemisegment. This suggested that a third bHLH proneural gene remained to be identified. Indeed, Goulding and colleagues (Goulding et al. 2000a) and Huang and colleagues (Huang et al. 2000) have recently reported the discovery of a gene highly related to ato, called amos, which is necessary and sufficient for the development of multidendritic neurons and the olfactory sense organs that do not require atonal.

The precursors of ESOs and CHOs are specified in similar ways (Fig. 2). Briefly, an equivalent group of cells initiates the expression of proneural genes and become endowed with neural potential. Interactions among these cells via the Delta-Notch pathway (Artavanis-Tsakonas et al. 1999/ refine the neural potential first to a subcluster, and then to a single cell. The selected cell delaminates and initiates a characteristic series of cell divisions to give rise to the appropriate sensory organ (Campos-Ortega and Knust 1990; Jan and Jan 1994; Vervoort et al. 1997; Culi and Modolell 1998). The pattern of cell division (Bodmer et al. 1989; Brewster and Bodmer 1996; Gho et al. 1999) is specific to each sensory organ type, as is the identity of the proneural gene expressed by the corresponding precursor (Fig. 2). Since ato is the proneural gene of CHOs, whereas the $A S-C$ genes specify the external sensory organs, proneural genes probably encode lineage identity information in flies (Jarman et al. 1993). This conclusion is supported by the fact that misexpression of scute can only give rise to ESOs, whereas misexpression of ato gives rise preferentially to CHOs, but also to ESOs (Jarman et al. 1993; Jarman and Ahmed 1998).

To determine if differences in the basic domain among the neuronal bHLH proteins account for their specificity, 
Figure 2. Different Drosophila proneural genes are required for the development of different PNS lineages. Whereas atonal is the proneural gene of CHOs, genes of the AS-C are required for ESOs. These two PNS organs have different lineage patterns and cell types as well as different morphologies.
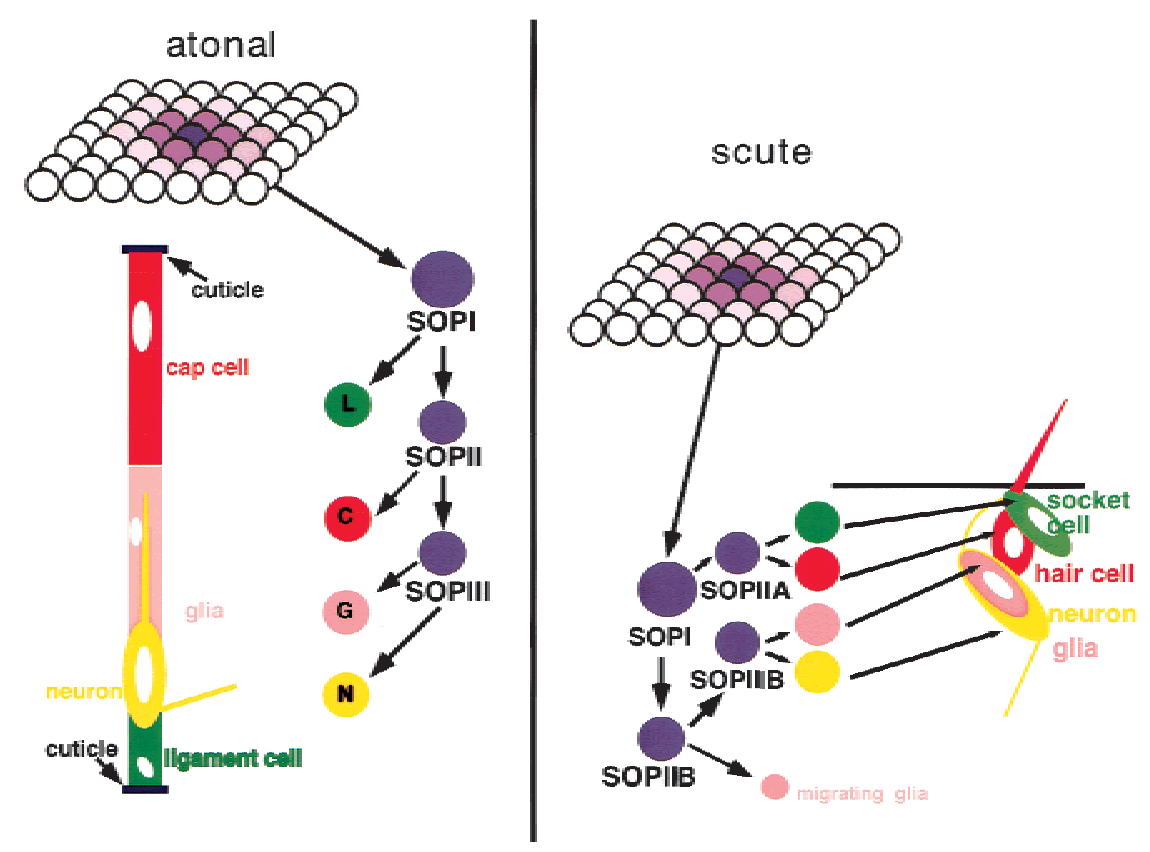

Chien and colleagues swapped the basic domains of ATO and Scute (Chien et al. 1996). As predicted, a Scute protein with an ATO basic domain was able to specify CHOs in an ato mutant embryo. Chien and colleagues also asked which residues contained the $\mathrm{CHO}$-specific information by making individual substitutions in the Scute basic domain. None of the single amino acid changes made in the Scute basic domain were sufficient to allow Scute to induce CHOs, suggesting that many of the residues may be important for lineage specificity. These data lead us to pose two questions: Does the basic domain of ATO encode a distinct set of instructions and, if so, is this set of instructions evolutionarily conserved?

The family tree: three branches

The identification of ARPs in vertebrates permits a comparative developmental and phylogenetic analysis of their structures (Fig. 3A) and functions. In examining the amino acid sequences of ARPs, we find that differences in the basic domain are sufficient to delineate the three different groups of ARPs by visual inspection (Fig. 1B) and phylogenetic analysis (Fig. 3B). ARPs may be grouped, by order of increasing sequence identity to the ATO basic domain, into three groups: the Neurogenin (NGN) group, the NeuroD group, and the ATO group (Fig. 1B).

Invariant residues of protein domains often indicate a conservation of function. Of the variable residues, it is those that vary according to a given pattern which tend to be most informative. All ARPs have seven invariant residues in the DNA binding basic domain (Fig. 1B) thought to contact DNA as based on the crystal structures of the MyoD and E47 proteins (Ellenberger et al. 1994; Ma et al. 1994) and a computer model of the ATO/ Daughterless heterodimer binding to DNA /Chien et al.
1996). In addition, ARPs have an invariant alanine at the fifth position (A5) which is not predicted to contact DNA. A5 is absent from the AS-C family, raising the question of whether it mediates recognition of, or affinity for, sequences surrounding the E box common to all ARPs, enabling them to bind regulatory regions differently from AS-C-related proteins (Van Doren et al.
A

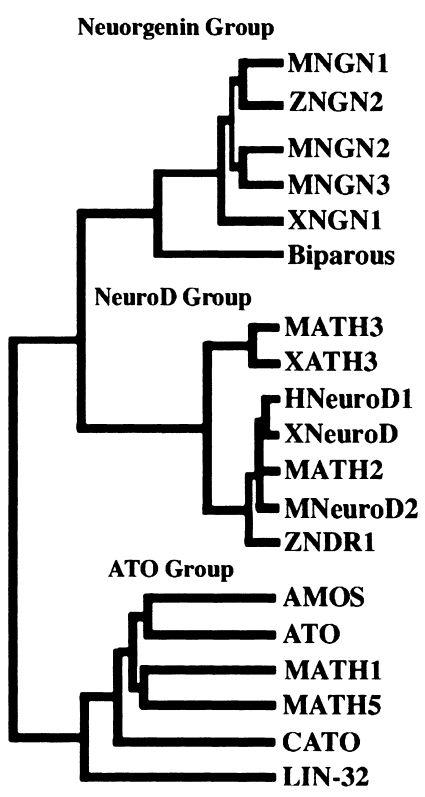

B

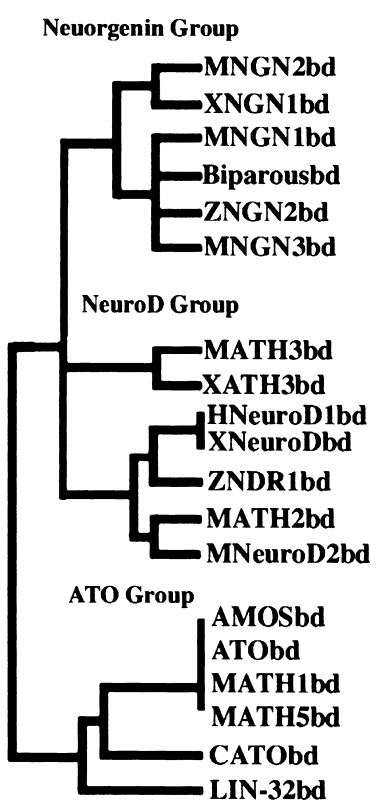

Figure 3. (A) Phylogenetic analysis of the ARPs' bHLH indicates three groups: the Neurogenin group, the NeuroD group, and the ATO group. (B) Phylogenetic analysis based on the basic domain alone is very similar to the one based on the entire bHLH, and classifies the ARPs into the same groups as in $A$. 
1994). It should be noted that A5 is also present in myogenic bHLH proteins (Fig. 1A). The alanines at positions four and seven (A4, A7) and the arginine at position 11 (R11) (Fig. 1B) vary among the ARPs but follow specific rules in their variations (see below). The leucine at position 3 (L3) appears to vary even within the same group (Fig. 1B). These observations suggest that A4, A7, and R11 may contribute to the functional specificity of each ARP group.

\section{The NGN group: vertebrate proneurals}

Among the ARPs, the NGN group is the most distantly related to ATO. These proteins share, on average, 53\% amino acid identity with ATO in the bHLH domain (Sommer et al. 1996). NGNs differ from ATO in four basic domain residues: L3 (variable), A4 $\rightarrow \mathrm{K} 4$, $\mathrm{A} 7 \rightarrow \mathrm{D} 7 / \mathrm{N} 7$ (the acidic and amide derivatives, respectively, of the same amino acid), and R11 $\rightarrow$ N11 (Fig. 1B). By structural criteria the NGN group includes one fly protein called Biparous (also known as TAP) (Bush et al. 1996; Gautier et al. 1997; Ledent et al. 1998), two Xenopus proteins (XNGN1a, XNGN1b) (Ma et al. 1996), one zebrafish protein (ZNGN1) (Blader et al. 1997), and three mouse proteins (NGN1, NGN2 and NGN3) (Ma et al. 1996; Sommer et al. 1996).

NGNs 1 and 2 have been shown to function as neuroblast selection genes in the mouse (Fode et al. 1998; Ma et al. 1998). They are required for the selection and delamination of neuroblasts during the development of several neuronal lineages including proximal and epibranchial placode-derived sensory ganglia (Fode et al. 1998; Ma et al. 1998), dorsal root ganglia (DRG) and the telencephalon (Ma et al. 1999). The different NGNs appear to be required for distinct subsets of neuronal populations. For example, whereas NGN1 is required for proximal cranial sensory ganglia (Ma et al. 1998), NGN2 is required for distal, epibranchial placode-derived, sensory ganglia (Fode et al. 1998). In DRG, NGN1 specifies TRKA positive cells, where as NGN2 specifies TRKBand TRKC-positive neurons (Ma et al. 1999). Nonetheless, there is overlap in expression pattern, and perhaps function, between the two genes. For instance, the early and transient defect in TRKB- and TRKC-positive DRG in NGN2 mutants is rescued by NGN1: The removal of both genes results in the loss of the entire DRG population. In addition, the two genes exhibit crossregulatory interactions in cranial ganglia and the neural crest similar to those observed between the AS-C proteins (Martinez and Modolell 1991; Fode et al. 1998; Ma et al. 1998). Finally, NGN1 and 2 are expressed in overlapping patterns in the dorsal telencephalon (Fode et al. 2000). Loss of NGN function in cranial ganglia results in the failure of all other neuronal markers to be expressed, as well as a severe reduction in the expression of the Notch ligand Delta-like1, suggesting failure of lateral signaling (Fode et al. 1998; Ma et al. 1998). These observations are consistent with a proneural function for the NGNs.

Evidence from other species suggests that NGNs may be neuroblast selection genes in most or all vertebrates.
Activation of Xenopus X-NGN-1 results in the activation of both lateral inhibition genes, such as X-Delta-1, as well as neuronal differentiation genes such as $X$ NeuroD and Xath3 (Ma et al. 1996; Takebayashi et al. 1997; Koyano-Nakagawa et al. 1999). Similarly in chick, in vivo ectopic activation of NGNs results in the expression of sensory neuronal markers, not only in ectodermal tissue, but also in mesodermally derived structures (Perez et al. 1999). These data are also consistent with proneural gene activity.

The NGN3 protein appears to play a precursor selection function in the mammalian pancreas. In the absence of the NGN3 none of the four endocrine cell types of the pancreas (alpha-, beta-, delta-, and pancreatic polypeptide cells) are generated (Gradwohl et al. 2000). Not surprisingly, NGN3 interacts with the Notch signaling pathway in this function (Apelqvist et al. 1999). Mouse NGN3 is also expressed in the nervous system (Sommer et al. 1996); however, its function in neurogenesis has not been determined. Therefore, in general, NGN expression and function appear to correlate with the specification of precursor cells.

The fly NGN-like protein, Biparous, presents an interesting case because it does not have a proneural function (Bush et al. 1996; Gautier et al. 1997; Ledent et al. 1998). Its embryonic expression appears to coincide with the distinction between neuronal versus glial precursor cells in the CNS (Bush et al. 1996). In the adult PNS, biparous is expressed in neurons innervating chemosensory organs (Gautier et al. 1997). Overexpression studies suggest that biparous may have a role in sugar and salt sensitivity of chemosensory organs (Ledent et al. 1998). Hence, the functions of Biparous are closer to those carried out by the vertebrate NeuroD proteins than they are to those of the NGN proteins (see below).

\section{The NeuroD group: genes of all trades}

Proteins of the NeuroD group share $\sim 57 \%$ amino acid identity with ATO in the bHLH domain (Lee 1997). Within the basic domain, the NeuroD group differs from ATO at three positions: L3 (variable), A4 $\rightarrow$ K4, and $\mathrm{R} 11 \rightarrow \mathrm{N} 11$. Notable exceptions to this rule are the ATO homologs, ATH2 and ATH3 proteins. In ATH2 A4 is replaced by an E, whereas in ATH3, R11 is substituted by a serine (in Xenopus XATH3) or a threonine (in mouse MATH3), suggesting that ATH3 may be regulated by phosphorylation. Indeed, the replacement of S11 by an aspartate, thereby mimicking phosphorylation, caused a strong reduction of XATH3 activity (Takebayashi et al. 1997).

The first NeuroD proteins were identified in mouse and Xenopus (Lee et al. 1995; Naya et al. 1995). The fly genomic database contains one putative protein of the NeuroD group related to ATH2 and ATH3. We therefore call this protein DATH23 (Fig. 1B). Three NeuroD-like transcripts have been found in zebrafish (ndr1a, ndr1b, and ndr2) (Liao et al. 1999) encoding proteins that are also related to the ATH2/ATH3 subgroup (Fig. 1B). Several chick, mouse, and human NeuroD proteins have 
been identified (NeuroD1, NeuroD2, NeuroM, ATH2, ATH3) (Bartholoma and Nave 1994; Shimizu et al. 1995; Roztocil et al. 1997; Takebayashi et al. 1997; Yan and Wang 1998).

The DATH23 basic domain reveals an interesting feature: It contains both substitutions characterizing the ATH2 and ATH3 proteins. Like ATH2 it has a glutamate at position four, and like ATH3 it has a threonine at position eleven that may be phosphorylated (Fig. 1B). The zebrafish proteins Zndr1 and Zndr2 are also related to ATH2 and ATH3, respectively. Phylogenetic analysis of bHLH of DATH23 suggests that this protein is equally related to all three ARP groups (Fig. 4A). However, a phylogenetic analysis based on the basic domain alone classifies DATH23 with MATH2. A careful examination of the bHLH domain reveals that the loop region shows clear distinctions between the ARP groups (Fig. 4B). The loop of DATH23 is more related to the NeuroD group than it is to the other two groups, showing that it is a member of the NeuroD group.

\section{A}

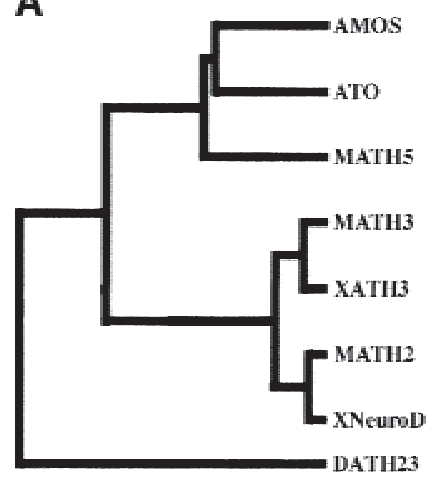

B

DATH23
XATH3
XneuorD
MATH2

AMOS
ATO
MATH5
Biparous
XNGN1
MNGN3

Figure 4. A novel NeuroD group protein in Drosophila. $(A)$ Phylogenetic analysis of the putative Drosophila protein DATH23 based on the bHLH (left) or the basic domain (right) shows differences in the classification of this protein. bHLH analysis classifies it separately from either the ATO or the NeuroD groups, whereas basic domain analysis classifies it with the NeuroD group. $(B)$ Conservation of key residues in the loop region shows that DATH23 belongs to the NeuroD group as suggested by the basic domain phylogenetic tree. Loop residues conserved in all ARPs are in blue, residues conserved in the NeuroD group are in red, in the ATO group in green, and in the NGN group in magenta.
NeuroDs are not proneural proteins. Their expression is activated after precursor selection and in their absence, precursor cells are specified. Furthermore, NeuroD expression generally depends on the proper expression of the upstream bHLH proteins such as the NGNs (Sommer et al. 1996). Most studies suggest that NeuroDs act as differentiation factors giving cells functional neuronal properties after their particular identities have been specified (Miyata et al. 1999; Perron et al. 1999; Liu et al. 2000). Studies of the function of the mouse Math2 gene suggest that NeuroD genes may have partially redundant functions during neurogenesis (Schwab et al. 1998). However, it has also been shown that in some instances, such as the vertebrate retina, NeuroD genes may play a role in terminal cell fate decisions such as neuronal versus glial cell fate (Morrow et al. 1999). NeuroD genes have also been shown to be required for neuronal differentiation and survival (Miyata et al. 1999). In other instances, absence of NeuroD leads to proliferation failure (Liu et al. 2000). In zebrafish, ndr1a and $n d r 1 b$ may be involved in olfactory development based on their expression pattern (Liao et al. 1999). The mouse NeuroD1 (also called BETA2) protein is involved in neuronal differentiation (Liu et al. 2000) as well as endocrine cell differentiation in the pancreas (Naya et al. 1997; Huang and Tsai 2000). In the nervous system, loss of NeuroD1 function results in dentate gyrus defects causing epilepsy in mutant mice. In the pancreas, NeuroD1 mutant mice showed a reduced number of beta cells that appear to die during differentiation, resulting in severe diabetes. Therefore, in contrast to the NGN group, it appears that the NeuroD genes have evolved to play multiple roles within and across different lineages. The comparison between the pancreatic defects of NGN3 mutant mice and NeuroD1 suggests that NeuroD proteins act downstream of NGNs, and may be among their transcriptional targets (Huang and Tsai 2000). This is supported by overexpression of NGNs, which results in the activation of NeuroDs in Xenopus, while the loss of NGN 1 and 2 results in the loss of NeuroD expression (Fode et al. 1998; Ma et al. 1998).

\section{The ATO group: basic identity}

The ATO group is comprised of one Caenorhabditis elegans protein, LIN-32 (Zhao and Emmons 1995), three Drosophila proteins, ATO, AMOS, and CATO (Jarman et al. 1993; Goulding et al. 2000a,b; Huang et al. 2000), and two chicken, Xenopus, mouse, and human proteins (ATH1 and ATH5) (Akazawa et al. 1995; Ben-Arie et al. 1996; Brown et al. 1998). Whereas LIN-32 is more closely related to the ATO group than it is to the NeuroD or NGN groups, it has a substitution at A7 akin to that usually found in the NGN group (A7 $\rightarrow$ D). LIN-32 has been shown to be required for the development of mechanosensory structures in the tail of the worm, called the sensory rays, and LIN-32 mutant worms are touch insensitive (Zhao and Emmons 1995).

Drosophila AMOS has a basic domain identical to that of ATO. amos is the proneural gene of the solitary dorsal 
bipolar multidendritic neurons (Huang et al. 2000) as well as two of the three types of olfactory sense organs found in the fly (Goulding et al. 2000a). Interestingly, the type of olfactory sense organs not specified by amos is specified by ato (Gupta and Rodrigues 1997).

cato does not appear to be a proneural gene, judging by its late expression pattern (Goulding et al. 2000b). The CATO basic domain differs from that of ATO in two positions, L3 and R11. In CATO, R11 is substituted by a lysine, a conservative substitution that is unlikely to affect the broad functional specificity of the cato basic domain. This is supported by the overexpression of cato which, like that of ato, results in the production of ectopic CHOs (Goulding et al. 2000b).

The vertebrate ATO group proteins, ATH1 and ATH5, have bHLH domains that share $67 \%$ and $71 \%$ amino acid identity with the bHLH domain of ATO, respectively (Akazawa et al. 1995; Ben-Arie et al. 1996; Brown et al. 1998). The basic domains of the three proteins (ATO, ATH1, and ATH5) are identical, suggesting that they all encode similar regulatory properties.

\section{Developmental MATH: one plus five equals ATO}

While the studies of Drosophila ato lead to the cloning of its vertebrate homologs, the studies on ATH1 and ATH5 in vertebrates offer insights into how some developmental mechanisms may be operating in Drosophila. Questions about the conservation of lineage identity information encoded by proneural genes are therefore becoming relevant.

\section{ATO and ATH1: I can't hear you}

CHOs are insect internal mechanoreceptor organs (Moulins 1976; McIver 1985). In adult flies, CHOs can be found underneath the body wall cuticle, in the joints, and in the second antennal segment. Body wall and joint CHOs are thought to act as mechanoreceptors for the sensory information generated by cuticle stretch and joint movement. CHOs in the antenna form the Johnston organ (JO), which mediates near-field hearing and vertical head positional information. Both ato mutant flies and flies with removed antennae are deaf (Dreller and Kirschner 1993; Eberl 1999) and show severe geotaxis abnormalities, indicating defects in vertical motion balance. Thus, by mediating hearing and balance functions, the JO shows striking functional similarities to the mammalian inner ear.

ato carries out two functions in $\mathrm{CHO}$ development; it is required for the selection of the $\mathrm{CHO}$ precursor cell and it defines $\mathrm{CHO}$ lineage identity. These two functions appear to be coupled in flies (Jarman et al. 1993; zur Lage and Jarman 1999). Although ATO's requirement for hearing organs is conserved in its vertebrate orthologs, this does not seem to be true of its precursor selection function. This is supported by three sets of observations.

First, the Xenopus ATO homolog 1 (XATH1) is expressed during frog ear development, however, its func- tion in that tissue remains unclear (Kim et al. 1997). Overexpression of XATH1 leads to the production of particular neuronal cell types distinct from those produced by other neural bHLH proteins. For example, although N-CAM and NeuroD are induced by NGN overexpression, they are not induced by XATH1, despite the clear transformation of ectoderm into neural tissue as marked by morphology and $\mathrm{N}$-tubulin expression. The authors propose that this distinction indicates that XATH1 encodes lineage information distinct from that encoded by other neural bHLH proteins.

The second observation that ato is specifically required for internal mechanoreceptors, as well as the auditory and geotaxis organ, gains particular significance in light of the studies on Math1. Math1 was first shown to be required for the development of the external granular layer of the mouse cerebellum (Ben-Arie et al. 1997). Subsequently however, Math1 was shown to be expressed in touch receptor cells located throughout the skin (Merkel cells) and in the auditory and vestibular sensory epithelia (Bermingham et al. 1999; Ben-Arie et al. 2000). Therefore, the association of ATO group proteins with internal mechanoreception, and specifically with hearing and balance, like their basic domain, is evolutionarily conserved.

The third observation is that Math1 determines the fate of the sensory hair cells in the mouse inner ear. Inner ear sensory epithelia are composed of two cell types: hair cells and supporting cells. Hair cells are the mechanoreceptor cells that convert sound or motion into neuronal activity via synapses with the neurons of the VIIIth cranial ganglion. Supporting cells appear to be important for the maintenance and function of hair cells (Goodyear and Richardson 1997; Torres and Giraldez 1998). Without hair cells vertebrates lack hearing and balance. Lineage studies suggest that hair and supporting cells are sibling cells produced by the division of a sensory mother cell (Fekete 1996). Studies from many laboratories (Adam et al. 1998; Haddon et al. 1998) indicate that the specification of inner ear hair cells require the Notch-Delta lateral signaling pathway. The current data support a model in which the daughters of the sensory mother cell signal each other through the Notch-Delta pathway. A single presumptive hair cell within a cluster inhibits the surrounding cells from taking on the hair cell fate (Corwin et al. 1991; Lewis 1991). In this context it was reasonable to postulate the existence of a bHLH gene which interacts with the Notch-Delta pathway, much like ato in Drosophila. This gene would assume the role of "pro-hair cell" gene. The expression of Math1 in the inner ear made it a logical candidate for such a role. Indeed, Math1 was shown to be necessary for the specification of all sensory hair cells in the sensory epithelia of inner ear sensory organs, both auditory and vestibular (Bermingham et al. 1999). Recent evidence suggests that Math1 is also sufficient for the specification of hair cells (Zheng and Gao 2000). In this instance, Math1 is playing a role quite similar in molecular terms to that of ato. However, in developmental terms there is an important distinction: ato specifies the $\mathrm{CHO}$ precursor cell 
as well as CHO lineage identity, whereas Math1 specifies the terminal mechanoreceptor cell itself (the hair cell). Studies of Math1 in the inner ear suggest that precursor specification and mechanoreceptor identity determination may have been uncoupled in mammalian PNS development. Whereas the loss of ato results in the elimination of the entire $\mathrm{CHO}$ starting with the sensory organ precursor cell (Jarman et al. 1993), the loss of Math1 deletes only one of the three cells that make up the sensory complex. In Math1 mutants the neurons that synapse with the hair cells and the supporting cells are both present, and only the hair cell is missing (Bermingham et al. 1999). Thus, ato specifies the entire mechanoreceptor organ whereas Math1 specifies only the terminal mechanoreceptor cell. Finally, expression of MATH1 in the fly can induce CHO formation in both normal (permissive) and ectopic (instructive) locations (Ben-Arie et al. 2000). These observations suggest that the coupling seen in flies between precursor selection and identity specification is not an inherent property of this group of genes.

Taken together, these sets of data suggest that the target pathways recognized by the two genes are not only conserved between flies and mice, but also lead to the formation of tissues with similar functions. In summary, involvement of ATO group proteins in hearing and vestibular organ development is an evolutionarily conserved phenomenon. In addition, overexpression studies suggest that ATO group proteins encode lineage identities distinct from that of other neuronal bHLH proteins.

In contrast to conservation of ATO group function in hearing and balance organ development, olfactory sense organ development does not seem to show the same pattern. Olfactory sense organs in Drosophila require the functions of the ATO group proteins ATO and AMOS (Gupta and Rodrigues 1997; Goulding et al. 2000a). In contrast, the development of the olfactory epithelium in mice requires the function of Mash1 (Guillemot et al. 1993). However, it cannot be ruled out that an ATO group protein similar to AMOS or ATO may act downstream of MASH1 in specifying the identity of terminal olfactory receptor cells. Given this apparent discrepancy it is possible to ask why MATH1 is treated as an ATO homolog and not as an AMOS homolog. By sequence alone these proteins are equally similar in the bHLH domain, and have identical basic domains. However, it is quite clear that the expression and function of MATH1 in skin mechanoreceptor cells and in inner ear sensory is very reminiscent of the expression of ATO. Therefore it seems reasonable to consider MATH1 a homolog of ATO.

\section{ATO and ATH5: the vision thing}

In Drosophila, ato is also the proneural gene of photoreceptors. ato mutants lack all larval and adult photoreceptors (Jarman et al. 1994; 1995; Daniel et al. 1999). However, ato does not directly instruct the fate of all photoreceptor cell types. Rather, it is required for the specification of the founder photoreceptor cell (the R8 cell), which then recruits the other photoreceptors (Dominguez et al. 1998). Overexpression of ato results in ectopic R8 cells and excessive neurogenesis (Dokucu et al. 1996). ato expression in the fly retina is mirrored, at least at the tissue level, by Ath5 expression in the vertebrate retina (Kanekar et al. 1997; Brown et al. 1998). This observation gave rise to the idea that during evolution ato duplicated into two genes, Ath1 and Ath5, with the latter mimicking ato's expression in the retina (BenArie et al. 2000). In this section we explore the functions of ato and Math5 in the development of the retina and the visual pathway.

In contrast to ato, Ath5 is not expressed in photoreceptor cells, but rather in retinal ganglion cells (RGCs) in mouse (Math5) and Xenopus (Xath5). Overexpression of XATH5 in retinal precursor cells leads to differentiation along the RGC fate, arguing that XATH5 is a key regulator of RGC identity (Kanekar et al. 1997). Similarly, the overexpression of ato in the Xenopus retina results in ectopic RGCs. It remains to be determined whether Math5 mutant mice specifically lack RGCs. Interestingly, there is a feature that is common between fly photoreceptors and RGCs. In flies, photoreceptors function both as the photoreceptive cells and as the neurons innervating the optic lobes of the CNS. In vertebrates, the two functions are performed separately by distinct cells, the photoreceptors and the retinal ganglion cells, which transmit visual information to the optic stations of the CNS (Lillien 1994; Morrow et al. 1999). This may be another example of the uncoupling of gene function as a result of the change in the developmental specificities of tissues and organisms. The function of Math5 in RGCs rather than photoreceptors may reflect a function for ato in the eye otherwise masked by its proneural requirement: ato is not required for photoreceptors because they are photoreceptors. Rather, it may be required for photoreceptors because, in flies, these are the cells sending the visual signal to the brain. Support for this notion comes from recent experiments by White and Jarman (2000). Using a mutation that affects ato expression in the R8 cell only after selection, they showed that many of the selected R8 cells exhibited functional as well as structural defects, indicating requirements for ato in establishing aspects of R8 identity. Alternatively, vertebrate photoreceptor cells may also require the function of an ATO group protein. Interestingly, MATH1 is expressed in the eye during embryonic development (N.A. Bermingham and H.Y. Zoghbi, pers. comm.), but it is unclear where exactly Math1 is expressed in the developing eye, or what its function is. Therefore, similar to hearing and balance, the use of the ATO group proteins has been conserved in retinal development, at least in the cells transmitting visual information.

\section{More to ATO than meets the eye}

Vision occupies a large part of the fly nervous system. This is intuitively obvious when one considers the size of the eyes relative to the rest of the head. In insects, visual information is relayed to the central brain via syn- 
aptic stations called the optic lobes. ATO is expressed in a region in the developing optic lobes called the inner proliferation center (IPC) where its function remains unclear (Jarman et al. 1993; Ben-Arie et al. 2000). In addition, Drosophila optic lobes are innervated by a cluster of neurons in the dorsolateral central brain called the dorsal cluster (DC), which also express ato (Hassan et al. 2000). Yet the expression and function of ATO is different in the DC than in the PNS. ATO is expressed initially in the embryonic precursor cells of the DC following their selection. The transient embryonic expression is terminated and remains silent until the third instar larval stage. ATO expression is then reinitiated in the differentiating DC neurons at the third instar stage. ATO expression persists in the DC neurons into adult life. In the absence of ATO the DC neurons are not lost, showing that ato is not required as a proneural gene in the DC lineage. Furthermore, loss and gain of function studies demonstrate that ATO expression in DC neurons is required for the proper arborization of neurites via an antagonistic interaction with Notch (Hassan et al. 2000). Interestingly, mammalian neurons also utilize the Notch pathway to regulate arborization (Franklin et al. 1999; Sestan et al. 1999), and for Math1 or other related bHLHs to play a role in this process would therefore not be surprising.

\section{Evo-devo}

Nothing in biology makes sense except in the light of evolution.

\section{Theodosius Dobzhansky}

The structural and functional comparative analysis of ARPs leads to some evolutionary implications worthy of consideration. There are at least two questions that emerge as potentially significant. The first is whether the lineage specificity of ATO group proteins is determined by the basic domain. The second is how the lineage identity relates to the precursor specification in flies and vertebrates. Future studies on the relationship between the NeuroD and NGN groups, and on the ability of different ATO-like proteins to mimic ATO in flies may begin to address the first question. The second question awaits identification of new vertebrate proneural genes and the analysis of their capacity to endow precursor cells with distinct identities.

\section{MATH1 and MATH5: miscalculated expression}

The expression of Math1 in joint cartilage and Math5 in the retina presents a dilemma: It appears that in both cases evolution has conserved the tissue expression pattern (joints and retina) but not the cell type expression pattern (CHOs vs. cartilage and photoreceptors vs. RGCs). In addition, the precursor specification function has not been conserved. It is possible to assume that this apparent dilemma is due to the intrinsic ability of the human mind to see relations where none exist. In other words the expression of Math1 and Math5 in cartilage and ganglion cells, respectively, may be an example of the use of an old gene in a novel cellular context. The conservation of tissue type may be the result of the existence of an ancestral body axis responsive enhancer element in ato that remained intact in Math1 and Math5. Given the conservation of the basic patterning pathways (such as Hox genes) it is not surprising that these genes are expressed in the same tissues, where they may be performing different functions.

In contrast to this apparent paradox, the expression and function of Math1 in the inner ear offers an excellent example of the conservation of tissue type expression, developmental function, and molecular interactions. Although there is no direct evidence to show that the mammalian inner ear and insect chordotonal organs evolved from a common ancestral sense organ, it is clear that hearing and chordotonal organs on the one hand, and hearing and ato on the other hand, are closely associated. In insects it is thought that hearing organs evolved at least 19 independent times. Yet, all hearing organs in insects have the same basic structure, and contain a chordotonal sensillum (van Staaden and Romer 1998; Yager 1999). Similarly, the gene that determines the identity of the hearing cell/organ has been identified in both flies and mice and in both cases it belongs to the ato group. Furthermore, the molecular mechanisms regulating the function of ato and Math1 in hearing cells are conserved. In both cases the interplay between the proneural gene on the one hand, and the Delta-Notch pathway on the other hand, results in the specification of the appropriately fated cell from an equivalence group. What remains to be determined is whether the downstream targets of ato and Math1 in the JO and the inner ear, respectively, are conserved. If the ability of Math1 to induce CHOs in flies is any indication, the answer is quite likely to be affirmative. Regardless of what molecular similarities may exist, it is quite remarkable that the expression of a single gene is so closely associated with a common functional outcome across such a large evolutionary time span.

\section{Proneural genes: identity crisis}

The idea of Drosophila proneural genes as subtype selector genes initially discussed in the context of the requirement of different proneural genes for different sensory organs (Jarman et al. 1993; Jarman and Jan 1995) appears to be gaining ground (Brunet and Ghysen 1999; Bray 2000). Numerous observations support the notion that the proneural genes themselves encode at least some information contributing to the specific identity of the lineages they specify. In the Drosophila PNS two families of proneural genes have been identified: the $A S$ - $C$ genes and the ato-related genes. Misexpression experiments demonstrate that the two groups encode distinct subtype identity information. Furthermore, genes within a family encode largely overlapping subtype instructions (Fig. 5B). Whereas the AS-C proteins generate ESOs, the ATO group proteins can specify CHOs, olfactory sense organs, and ESOs (Rodriguez et al. 1990; Brand et al. 1993; Jar- 
man et al. 1993; Chien et al. 1996; Jarman and Ahmed 1998; Goulding et al. 2000a,b; Huang et al. 2000). The studies by Chien and colleagues (1996) suggest that the differences in the basic domain between the two classes may be sufficient to explain these differential activities. One puzzle remains, however. The distinction between ESOs and CHOs has been shown to require the homeobox gene cut. The loss of cut transforms ESOs into $\mathrm{CHOs}$, and its ectopic expression transforms $\mathrm{CHOs}$ into ESOs (Bodmer et al. 1987; Blochlinger et al. 1990). Jarman and Ahmed (1998) have shown that the misexpression of ATO represses cut expression. This however leads to the following paradox: If ATO represses cut, and cut is necessary for ESO fate, then how can ATO expression produce ectopic ESOs? To explain this, Jarman and Ahmed propose that at subthreshold levels ATO is insufficient to repress cut, but sufficient to promote neurogenesis resulting in default ESOs.

Although ATO and AMOS can produce essentially the same types of sense organs, a notable difference exists. AMOS can induce the formation of all subtypes of olfactory sense organs (coeloconica, basiconica, and trichodea), whereas ATO can only produce one subtype (coeloconica) (Goulding et al. 2000a). This distinction between ATO and AMOS activities is not likely to reside in the basic domain, suggesting that sequences outside the basic domain may play a role in modulating differential regulatory properties of very similar bHLH proteins. Formation of multidendritic neurons presents a further complication. Multidendritic neurons are generated, depending on their location, by precursors expressing AS-C proteins, ATO, and AMOS. (Jarman et al. 1993; Brewster and Bodmer 1995; Huang et al. 2000). Yet, only AMOS specifies ectopic multidendritic neurons and induces the expression of a multidendritic neuron-specific marker (Huang et al. 2000).

A similar "promiscuous" situation exists in $\mathrm{CHO}$ development. At least one $\mathrm{CHO}$ is observed in the absence of ATO function, and at least one is often missing in AS-C mutants. In the combined absence of ATO and the AS-C, all CHOs are lost (Jarman et al. 1993). The CHO unaffected by the loss of ATO is produced from a precursor cell called the P cell, which expresses both ATO and AS-C proteins. Interestingly this cell also expresses CATO after it is selected independently of ATO function (Goulding et al. 2000b). Goulding and colleagues propose that in the absence of ATO, CATO provides $\mathrm{CHO}$ identity, while the AS-C proteins perform the proneural function. These data are consistent with the uncoupling model and show that even in Drosophila, at least in the case of the P cell, precursor selection and identity specification can be separated.

Do vertebrate proneural genes also encode neuronal identity information? Some evidence suggests that they may. For instance, whereas MASH1 is required for the development of the autonomic nervous system (Guillemot et al. 1993), the NGNs are required for the development of DRG and cranial sensory ganglia (Fode et al. 1998; Ma et al. 1998). Similarly, in the olfactory epithelium, MASH1 and Ngn2 are expressed in mutually ex- clusive domains. However, NGN1 is expressed coincidentally with MASH1 and may be dependent on it in at least some lineages (Cau et al. 1997, 2000). Finally, ectopic expression of NGN in the chick specifically results in the activation of sensory, rather than autonomic, neuron markers and biases migrating crest cells to localize to DRG. These data suggest that MASH1 and NGNs generally specify distinct fates.

The central problem of this comparison, however, is that there is no evidence to suggest that Mash1 is a neuroblast selection gene. On the contrary, studies show that the initial steps of neurogenesis in Mash1 mutants are unaffected, and that failure of cells to acquire their proper functional identities results in their degeneration (Guillemot et al. 1993; Blaugrund et al. 1996; Cau et al. 1997; Hirsch et al. 1998). Another problem relates to the regulation of the subtype selector gene Phox $2 a$. Phox $2 a$ is expressed in PNS cells that develop a noradrenergic phenotype. However, the autonomic lineages are MASH1 dependent, whereas the cranial lineages are NGN2 dependent. Yet, phox2a expression is dependent on MASH1 in the autonomic nervous system, but independent of NGN2 in cranial ganglia. This suggests that MASH1, but not NGN2, encodes the set of instructions necessary for the noradrenergic phenotype. At this point, the proneural genes of MASH1 dependent lineages, if any exist, remain unidentified. Therefore, discovering whether there are other proneural genes in vertebrates and determining what proteins they encode is key to a clear resolution of the question of fate specification in vertebrate neurogenesis. Finally, the uncoupling of the neuroblast determination properties and cell type identity functions in the ATO orthologs MATH1 and MATH5 suggests that it may be more appropriate to draw comparisons between MATH1 and MASH1, than between MASH1 and NGNs.

\section{The bHLH: evolutionary uncoupling tool}

We propose that the basic helix-loop-helix region functions as an uncoupling device with at least two components. The lineage identity component is the DNA-binding basic domain: Its conservation is necessary for subtype information, but not sufficient for precursor selection. The fact that Math1 acts in terminal cell fate specification in the inner ear sensory epithelium suggests that the association between ato and Math1 on the one hand, and mechanoreception on the other, is not tied to precursor selection. The precise implication of this association must await the elucidation of Math1 function in the skin and joints, and the discovery of downstream targets. Similarly, the link between ato and eye development does not lie in photoreception per se, but perhaps in the transmission of visual information from the eye to the brain. This is suggested by the expression of Math5 in the RGCs, and by the expression and function of ato in the selected R8 cells. In support of this notion, misexpression of XATH5 and ATO in Xenopus produces ectopic RGCs. The relationship between ato and Math5 on the one hand, and transmission of visual 


\section{Environmental Signals Neural Competence}

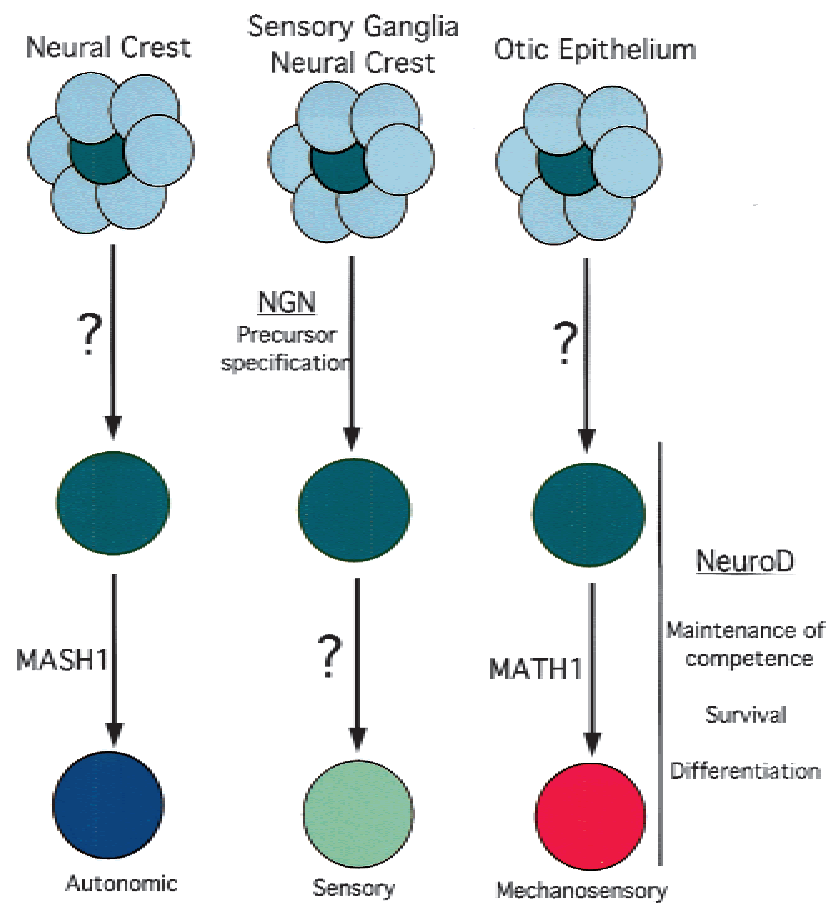

Figure 5. A working model for neuronal identity specification in vertebrate neurogenesis. Environmental signals endow cells with the capacity to form neuronal progenitors, or neuroblasts. A process of lateral inhibition results in the selection of a single neuroblast that, in many cases, is able to give rise to a variety of lineages. In cranial and dorsal root ganglia, the NGN proteins are required for neuroblast selection. The sensory identity may be the result of the presence of a sensory specific identity factor activated by the NGNs, or the absence of alternative identity factors. Expression of MASH1 in selected neuroblasts, or their progeny, biases the developing lineages to adopt an autonomic identity. In the otic vesicle, MATH1 is expressed in the sensory epithelial progeny of a neuroblast selected by unknown proneural genes. MATH1 expression biases the nascent cells to adopt a mechanosensory fate and develop into hair cells. In all lineages, neuronal competence, survival, and differentiation are mediated by the expression of the NeuroD group of proteins.

information on the other, is also not tied to a precursor determination function.

The second component of the uncoupling tool is probably the HLH or a subdomain of it. Switching the basic domains of Scute and ATO does not interfere with their capacity to induce neurogenesis, but it does transform their lineage identity information. Therefore, separating the basic domain from the HLH separates the neuronal precursor determination function from the lineage identity specification function. In flies, however, current data suggest a model (Fig. 2) in which precursor determination and lineage identity information are simultaneous products of the expression of proneural genes. Therefore, once a precursor cell has initiated the expression of a particular proneural gene, it becomes commit- ted to a specific fate. Thus, although neurogenic capacity and subtype specificity can be separated in flies, it is not clear that they normally are. One of the drawbacks of addressing the uncoupling issue in the fly PNS is that neuronal precursor determination and lineage subtype specification occur in the same cell over a short time window. If the two processes are in fact genetically separable, one might predict the existence of a neuronal precursor-specific protein whose function it is to interact with all proneural proteins and mediate their capacity to generate a precursor cell.

In the vertebrate PNS the uncoupling is manifest at the molecular and cellular levels. The data presented in this review suggest a model (Fig. 5) in which vertebrate neuronal lineage development is initiated by the determination of multipotent precursors via the action of the NGNs, and as of yet unidentified proneural genes. The general neuronal character, and the survival of these precursors, is maintained by the NeuroD genes, probably direct transcriptional targets of the NGNs. As the selected precursors divide and differentiate, cell type identities are specified by the actions of potentially independently regulated bHLH genes such as Mash1, Math1, and Math5. In this context, it would be particularly interesting to determine whether NGN3 can compensate for NGN1 and NGN2, and whether the missing proneural genes also belong to the NGN group. It should be emphasized that the model presented in Figure 5 cannot be extrapolated to the vertebrate CNS where bHLH proteins appear to play distinct roles in different tissues.

If the bHLH is indeed an evolutionary uncoupling tool, it is easy to imagine that its domains are under separate evolutionary pressures. If this is the case, it would be interesting to determine whether vertebrate bHLH identity genes, such as Mash1 and Math1, have retained their capacity for neuroblast determination in a vertebrate context. Similarly, it is unclear whether vertebrate NGNs and NeuroDs can produce ectopic neurogenesis in flies, and if so, what organ types will be specified.

\section{Acknowledgments}

We thank Olivier Lichtarge, David Anderson, and especially Andrew Jarman for insightful discussions, Huda Zoghbi and Ming-Jer Tsai for comments on the manuscript, Matthew Kelley, Nessan Bermingham, and Huda Zoghbi for sharing unpublished data, and Salpy Sarikhanian for help with manuscript preparation. B.H is supported by the NIH. This work is supported in part by a NASA grant to H.J.B.

\section{References}

Adam, J., Myat, A., Le Roux, I., Eddition, M., Henrique, D., Ish-Horowicz, D., and Lewis, J. 1998. Cell fate choices and the expression of Notch, Delta and Serrate homologues in the chick inner ear: Parallels with Drosophila sense-organ development. Development 125: 4645-4654.

Akazawa, C., Ishibashi, M., Shimizu, C., Nakanishi, S., and Kageyama, R. 1995. A mammalian helix-loop-helix factor structurally related to the product of Drosophila proneural gene atonal is a positive transcriptional regulator expressed in the developing nervous system. J. Biol. Chem. 270: 8730- 
8738.

Anderson, D.J. 1995. Neural development. Spinning skin into neurons. Curr. Biol. 5: 1235-1238.

Apelqvist, A., Li, H., Sommer, L., Beatus, P., Anderson, D.J., Honjo, T., Hrabe de Angelis, M., Lendahl, U., and Edlund, H. 1999. Notch signalling controls pancreatic cell differentiation. Nature 400: 877-881.

Artavanis-Tsakonas, S., Rand, M.D., and Lake, R.J. 1999. Notch signaling: Cell fate control and signal integration in development. Science 284: 770-776.

Baer, R. 1993. TAL1, TAL2 and LYL1: A family of basic helixloop-helix proteins implicated in $\mathrm{T}$ cell acute leukaemia. Semin. Cancer Biol. 4: 341-347.

Bartholoma, A. and Nave, K.A. 1994. NEX-1: A novel brainspecific helix-loop-helix protein with autoregulation and sustained expression in mature cortical neurons. Mech. Dev. 48: 217-228.

Ben-Arie, N., McCall, A., Berkman, S., Eichele, G., Bellen, H.J., and Zoghbi, H.Y. 1996. Evolutionary conservation of sequence and expression of the bHLH protein ATONAL suggests that it plays a role in neurogenesis. Hum. Mol. Genet. 5: 1207-1216.

Ben-Arie, N., Bellen, H.J., Armstrong, D.L., McCall, A.E., Gordadze, P.R., Guo, Q., Matzuk, M.M., and Zoghbi, H.Y. 1997. Math1 is essential for genesis of cerebellar granule neurons. Nature 390: 169-172.

Ben-Arie, N., Hassan, B.A., Bermingham, N.A., Malicki, D.M., Armstrong, D., Matzuk, M., Bellen, H.J., and Zoghbi, H.Y. 2000. Functional conservation of atonal and Math1 in the CNS and PNS. Development 127: 1039-1048.

Bermingham, N.A., Hassan, B.A., Price, S.D., Vollrath, M.A., Ben-Arie, N., Eatock, R.A., Bellen, H.J., Lysakowski, A., and Zoghbi, H.Y. 1999. Math1, an essential gene for the generation of inner ear hair cells. Science 284: 1837-1841.

Blackwell, T.K., Kretzner, L., Balckwood, E.M., Eisenman, R.N., and Weintraub, H. 1990. Sequence-specific DNA binding by the c-Myc protein. Science 250: 1149-1151.

Blader, P., Fischer, N., Gradwohl, G., Guillemot, F., and Strahle, U. 1997. The activity of Neurogenin 1 is controlled by local cues in the zebrafish embryo. Development 124: 4557-4569.

Blaugrund, E., Pham, T.D., Tennyson, V.M., Lo, L., Sommer, L., Anderson, D.J., and Gershon, M.D. 1996. Distinct subpopulations of enteric neuronal progenitors defined by time of development, sympathoadrenal lineage markers and Mash1-dependence. Development 122: 309-320.

Blochlinger, K., Bodmer, R., Jan, L.Y., and Jan, Y.N. 1990. Patterns of expression of Cut, a protein required for external sensory organ development, in wild type and cut mutant embryos. Genes \& Dev. 4: 1322-1331.

Bodmer, R., Barbel, S., Shepherd, S., Jack, J.W., Jan, L.Y., and Jan, Y.N. 1987. Transformation of sensory organs by mutations of the cut locus of D. melanogaster. Cell 51: 293-307.

Bodmer, R., Carretto, R., and Jan, Y.N. 1989. Neurogenesis of the peripheral nervous system in Drosophila embryos: DNA replication patterns and cell lineages. Neuron 3: 21-32.

Brand, M., Jarman, A.P., Jan, L.Y., and Jan, Y.N. 1993. asense is a Drosophila neural precursor gene and is capable of initiating sense organ formation. Development 119: 1-17.

Bray, S. 2000. Specificity and promiscuity among proneural proteins. Neuron 25: 1-5.

Brewster, R. and Bodmer, R. 1995. Origin and specification of type II sensory neurons in Drosophila. Development 121: 2923-2936.

-1996. Cell lineage analysis of the Drosophila peripheral nervous system. Dev. Genet. 18: 50-63.

Brown, N.L., Kanekar, S., Vetter, M.L., Tucker, P.K., Gemza,
D.L., and Glaser, T. 1998. Math5 encodes a murine basic helix-loop-helix transcription factor expressed during early stages of retinal neurogenesis. Development 125: 48214833.

Brunet, J.-F. and Ghysen, A. 1999. Deconstructing cell determination: Proneural genes and neuronal identity. BioEssays 21: 313-318.

Bush, A., Hiromi, Y., and Cole, M. 1996. biparous: A novel bHLH gene expressed in neuronal and glial precursors in Drosophila. Dev. Biol. 180: 759-772.

Cabrera, C.V. and Alonso, M.C. 1991. Transcriptional activation by heterodimers of the achaete-scute and daughterless gene products of Drosophila. EMBO J. 10: 2965-2973.

Campos-Ortega, J.A. and Knust, E. 1990. Genetic and molecular mechanisms of neurogenesis in Drosophila melanogaster. I. Physiol. 84: 1-10.

Campuzano, S. and Modolell, J. 1992. Patterning of the Drosophila nervous system: The achaete-scute gene complex. Trends Genet. 8: 202-208.

Cau, E., Gradwohl, G., Fode, C., and Guillemot, F. 1997. Mash1 activates a cascade of bHLH regulators in olfactory neuron progenitors. Dev. Suppl. 124: 1611-1621.

Cau, E., Gradwohl, G., Casarosa, S., Kageyama, R., and Guillemot, F. 2000. Hes genes regulate sequential stages of neurogenesis in the olfactory epithelium. Development 127: 2323-2332.

Caudy, M., Vaessin, H., Brand, M., Tuma, R., Jan, L.Y., and Jan, Y.N. 1988. daughterless, a Drosophila gene essential for both neurogenesis and sex determination, has sequence similarities to myc and the achaete-scute complex. Cell 55: 1061-1067.

Chien, C.T., Hsiao, C.D., Jan, L.Y., and Jan, Y.N. 1996. Neuronal type information encoded in the basic-helix-loop-helix domain of proneural genes. Proc. Nat1. Acad. Sci. 93: 1323913244.

Chitnis, A.B. 1999. Control of neurogenesis-lessons from frogs, fish and flies. Curr. Opin. Neurobiol. 9: 18-25.

Corwin, J.T., Jones, J.E., Katayama, A., Kelley, M.W., and Warchol, M.E. 1991. Hair cell regeneration: The identities of progenitor cells, potential triggers and instructive cues. (ed. G.R. Bock). Whelan J. Chichester, England.

Culi, J. and Modolell, J. 1998. Proneural gene self-stimulation in neural precursors: An essential mechanism for sense organ development that is regulated by Notch signaling. Genes \& Dev. 12: 2036-2047.

Dambly-Chaudiere, C. and Ghysen, A. 1987. Independent subpatterns of sense organs require independent genes of the achaete-scute complex in Drosophila. Genes \& Dev. 1: 297306.

Daniel, A., Dumstrei, K., Lengyel, J.A., and Hartenstein, V. 1999. The control of cell fate in the embryonic visual system by atonal, tailless and EGFR signaling. Development 126: 2945-2954.

Davis, R.L. and Weintraub, H. 1992. Acquisition of myogenic specificity by replacement of three amino acid residues from MyoD into E12. Science 256: 1027-1030.

Davis, R.L., Cheng, P.F., Lassar, A.B., Thayer, M., Tapscott, S., and Weintraub, H. 1989. MyoD and achaete-scute: 4-5 amino acids distinguishes myogenesis from neurogenesis. Princess Takamatsu Symp. 20: 267-278.

Davis, R.L., Cheng, P.-F., Lassar, A.B., and Weintraub, H. 1990. The MyoD DNA binding domain contains a recognition code for muscle-specific gene activation. Cell 60: 733-746.

Dias, P., Dilling, M., and Houghton, P. 1994. The molecular basis of skeletal muscle differentiation. Semin. Diagn. Pathol. 11: 3-14. 
Dokucu, M.E., Zipursky, S.L., and Cagan, R.L. 1996. Atonal, rough and the resolution of proneural clusters in the developing Drosophila retina. Development 122: 4139-4147.

Dominguez, M., Wasserman, J.D., and Freeman, M. 1998. Multiple functions of the EGF receptor in Drosophila eye development. Curr. Biol. 8: 1039-1048.

Dreller, C. and Kirschner, W.H. 1993. Hearing in honeybees: Localization of the audiotory sense organ. J. Comp. Physiol. A 173: 275-279.

Eberl, D.F. 1999. Feeling the vibes: Chordotonal mechanisms in insect hearing. Curr. Opin. Neurobiol. 9: 389-393.

Ellenberger, T., Fass, D., Arnaud, M., and Harrison, S.C. 1994. Crystal structure of transcription factor E47: E-box recognition by a basic region helix-loop-helix dimer. Genes \& Dev. 8: 970-980.

Fekete, D.M. 1996. Cell fate specification in the inner ear. Curr. Opin. Neurobiol. 6: 533-541.

Fisher, A. and Caudy, M. 1998. The function of hairy-related bHLH repressor proteins in cell fate decisions. BioEssays 20: 298-306.

Fode, C., Gradwohl, G., Morin, X., Dierich, A., LeMeur, M., Goridis, C., and Guillemot, F. 1998. The bHLH protein NEUROGENIN 2 is a determination factor for epibranchial placode-derived sensory neurons. Neuron 20: 483-494.

Fode, C., Ma, Q., Casarosa, S., Ang, S.-L., Anderson, D.J., and Guillemot, F. 2000. A role for neural determination genes in specifying the dorsoventral identity of telencephalic neurons. Genes \& Dev. 14: 67-80.

Franklin, J.L., Berechid, B.E., Cutting, F.B., Presente, A., Chambers, C.B., Foltz, D.R., Ferreira, A., and Nye, J.S. 1999. Autonomous and non-autonomous regulation of mammalian neurite development by Notch1 and Delta1. Curr. Biol. 9: 1448-1457.

Garcia-Bellido, A. 1979. Genetic analysis of the achaete-scute system of Drosophila melanogaster. Genetics 91: 491-520.

Garcia-Bellido, A. and Santamaria, P. 1978. Developmental analysis of the achaete-scute system of Drosophila melanogaster. Genetics 88: 469-486.

Gautier, P., Ledent, V., Massaer, M., Dambly-Chaudiere, C., and Ghysen, A. 1997. tap, a Drosophila bHLH gene expressed in chemosensory organs. Gene 191: 15-21.

Gho, M., Bellaiche, Y., and Schweisguth, F. 1999. Revisiting the Drosophila microchaete lineage: A novel intrinsically asymmetric cell division generates a glial cell. Development 126: 3573-3584.

Ghysen, A. and Dambly-Chaudiere, C. 1989. Genesis of the Drosophila peripheral nervous system. Trends Genet. 5: 251-255.

Goodyear, R. and Richardson, G. 1997. Pattern formation in the basilar papilla: Evidence for cell rearrangement. J. Neurosci. 17: 6289-6301.

Goulding, S.E., zur Large, P., and Jarman, A.P. 2000a. amos, a proneural gene for Drosophila olfactory sense organs that is regulated by lozenge. Neuron 25: 69-78.

Goulding, S.E., White, N.M., and Jarman, A.P. 2000b. cato encodes a basic-helix-loop-helix transcription factor implicated in the correct differentiation of Drosophila sense organs. Dev. Biol. 221: 120-131.

Gradwohl, G., Dierich, A., LeMeur, M., and Guillemot, F. 2000. neurogenin3 is required for the development of the four endocrine cell lineages of the pancreas. Proc. Natl. Acad. Sci. 97: 1607-1611.

Guillemot, F. 1999. Vertebrate bHLH genes and the determination of neuronal fates. Exp. Cell. Res. 253: 357-364.

Guillemot, F., Lo, L.-C., Johnson, J.E., Auerbach, A., Anderson, D.J., and Joyner, A. 1993. Mammalian achaete-scute homo- $\log 1$ is required for the early development of olfactory and autonomic neurons. Cell 75: 463-476.

Gupta, B.P. and Rodrigues, V. 1997. Atonal is a proneural gene for a subset of olfactory sense organs in Drosophila. Genes Cells 2: 225-233.

Haddon, C., Jiang, Y.J., Smithers, L., and Lewis, J. 1998. DeltaNotch signaling and the patterning of sensory cell differentiation in the zebrafish ear: Evidence from the mind bomb mutant. Development 125: 4637-4644.

Hassan, B. and Vaessin, H. 1996. Regulatory interactions during early neurogenesis in Drosophila. Dev. Genetics 18: 18-27.

Hassan, B.A., Bermingham, N.A., He, Y., Sun, Y., Jan, Y.-N., Zoghbi, H.Y., and Bellen, H.J. 2000. atonal regulates axonal arborization but does not act as a proneural gene in the Drosophila brain. Neuron 25: 549-561.

Hinz, U. 1997. On the function of proneural genes in Drosophila. Perspect. Dev. Neurobiol. 4: 273-284.

Hinz, U., Giebel, B., and Campos-Ortega, J.A. 1994. The basichelix-loop-helix domain of Drosophila lethal of scute protein is sufficient for proneural function and activates neurogenic genes. Cell 76: 77-87.

Hirsch, M.R., Tiveron, M.C., Guillemot, F., Brunet, J.F., and Goridis, C. 1998. Control of noradrenergic differentiation and Phox2a expression by MASH1 in the central and peripheral nervous system. Development 125: 599-608.

Huang, H. and Tsai, M. 2000. Transcription factors involved in pancreatic islet development. J. Biomed. Sci. 7: 27-34.

Huang, M.-L., Hsu, C.-H., and Chien, C.-T. 2000. The proneural gene amos promotes multiple dendritic neuron formation in the Drosophila peripheral nervous system. Neuron 25: $57-$ 67.

Jan, L.Y. and Jan, Y.N. 1993. The peripheral nervous system. (ed. M.B.A. Martinez-Arias). Cold Spring Harbor Laboratory Press, Cold Spring Harbor, NY.

. 1994. Neuronal cell fate specification in Drosophila. Curr. Opin. Neurobiol. 4: 8-13.

Jarman, A.P. and Ahmed, I. 1998. The specificity of proneural genes in determining Drosophila sense organ identity. Mech. Dev. 76: 117-125.

Jarman, A.P. and Jan, Y.N. 1995. Multiple roles for proneural genes in Drosophila neurogenesis. (ed. B.H.J. Juurlink, P.H. Krone, W.M Kulyk, V.M.K. Verge, and J.R. Doucette). Plenum, New York, NY.

Jarman, A.P., Grau, Y., Jan, L.Y., and Jan, Y.N. 1993. atonal is a proneural gene that directs chordotonal organ formation in the Drosophila peripheral nervous system. Cell 73: 13071321.

Jarman, A.P., Grell, E.H., Ackerman, L., Jan, L.Y., Jan, Y.N. 1994. Atonal is the proneural gene for Drosophila photoreceptors. Nature 369: 398-400.

Jarman, A.P., Sun, Y., Jan, L.Y., and Jan, Y.N. 1995. Role of the proneural gene, atonal, in formation of Drosophila chordotonal organs and photoreceptors. Development 121: 20192030.

Kageyama, R., Ishibashi, M., Takebayashi, K., and Tomita, K. 1997. bHLH transcription factors and mammalian neuronal differentiation. Int. J. Biochem. Cell Biol. 29: 1389-1399.

Kanekar, S., Perron, M., Dorsky, R., Harris, W.A., Jan, L.Y., Jan, Y.N., and Vetter, M.L. 1997. Xath5 participates in a network of bHLH genes in the developing Xenopus retina. Neuron 19: 981-994.

Kerkhoff, E., Bister, K., and Klempnauer, K.H. 1991. Sequencespecific DNA binding by Myc proteins. Proc. Natl. Acad. Sci. 88: 4323-4327.

Kim, P., Helms, A.W., Johnson, J.E., and Zimmerman, K. 1997. XATH-1, a vertebrate homolog of Drosophila atonal, in- 
duces a neuronal differentiation within ectodermal progenitors. Dev. Biol. 187: 1-12.

Koyano-Nakagawa, N., Wettstein, D., and Kintner, C. 1999. Activation of Xenopus genes required for lateral inhibition and neuronal differentiation during primary neurogenesis. Mol. Cell. Neurosci. 14: 327-339.

Ledent, V., Gaillard, F., Gautier, P., Ghysen, A., and DamblyChaudiere, C. 1998. Expression and function of tap in the gustatory and olfactory organs of Drosophila. Int. J. Dev. Biol. 42: 163-170.

Lee, J.E. 1997. NeuroD and neurogenesis. Dev. Neurosci. 19: 27-32.

Lee, J.E., Hollenberg, S.M., Snider, L., Turner, D.L., Lipnick, N., and Weintraub, H. 1995. Conversion of Xenopus ectoderm into neurons by NeuroD, a basic helix-loop-helix protein. Science 268: 836-844.

Lewis, J. 1991. Rules for the production of sensory cells. Ciba Found. Symp. 160: 25-39.

Liao, J., He, J., Yan, T., Korzh, V., and Gong, Z. 1999. A class of NeuroD-related basic helix-loop-helix transcription factors expressed in developing central nervous system in zebrafish. DNA Cell Biol. 18: 333-344.

Lillien, L. 1994. Neurogenesis in the vertebrate retina. Perspect. Dev. Neurobiol. 2: 175-182.

Liu, M., Pleasure, S.J., Collins, A.E., Noebels, J.L., Naya, F.J., Tsai, M.J., and Lownstein, D.H. 2000. Loss of BETA2/NeuroD leads to malformation of the dentate gyrus and epilepsy. Proc. Natl. Acad. Sci. 97: 865-870.

Ma, A., Moroy, T., Collum, R., Weintraub, H., Alt, F.W., and Blackwell, T.K. 1993. DNA binding by $\mathrm{N}$ - and L-Myc proteins. Oncogene 8: 1093-1098.

Ma, P.C.M., Rould, M.A., Weintraub, H., and Pabo, C.O. 1994. Crystal structure of MyoD bHLH domain-DNA complex: Perspectives on DNA recognition and implications for transcriptional activation. Cell 77: 451-459.

Ma, Q., Kintner, C., and Anderson, D.J. 1996. Identification of neurogenin, a vertebrate neuronal determination gene. Cell 87: 43-52.

Ma, Q., Chen, Z., del Barco Barrantes, I., de la Pompa, J.L., and Anderson, D.J. 1998. Neurogenin1 is essential for the determination of neuronal precursors for proximal cranial sensory ganglia. Neuron 20: 469-482.

Ma, Q., Fode, C., Guillemot, F., and Anderson, D.J. 1999. Neurogenin 1 and Neurogenin 2 control two distinct waves of neurogenesis in developing dorsal root ganglia. Genes \& Dev. 13: 1717-1728.

Malicki, M.T., Jhala, U.S., Antonellis, A., Fields, L., Doria, A., Orban, T., Saad, M., Warram, J.H., Montminy, M., and Krolewski, A.S. 1999. Mutations in NeuroD1 are associated with the development of type 2 diabetes mellitus. Nat. Genet. 23: 323-328.

Martinez, C. and Modolell, J. 1991. Cross-regulatory interactions between the proneural achaete and scute genes of Drosophila. Science 251: 1485-1487.

McIver, S.B. 1985. Mechanoreception. In Comprehensive insect physiology, biochemistry and pharmacology (ed. L.I. Gilbert and D.A. Kerkut), pp. 71-132. Pergamon Press, New York, NY.

Miyata, T., Maeda, T., and Lee, J.E. 1999. NeuroD is required for differentiation of the granule cells in the cerebellum and hippocampus. Genes \& Dev. 13: 1647-1652.

Modolell, J. and Campuzano, S. 1998. The achaete-scute complex as an integrating device. Int. J. Dev. Biol. 42: 275-282.

Morrow, E.M., Furukawa, T., Lee, J.E., and Cepko, C.L. 1999. NeuroD regulates multiple functions in the developing neural retina in rodent. Development 126: 23-36.
Moulins, M. 1976. Ultrastructure of chordotonal organs. (ed. P.J. Mill). Chapman and Hall, London, UK.

Murre, C., Schonleber McCaw, P., and Baltimore, D. 1989a. A new DNA binding and dimerization motif in immunoglobulin enhancer binding, daughterless, MyoD, and myc proteins. Cell 56: 777-783.

Murre, C., Schonleber McCaw, P., Vaessin, H., Caudy, M., Jan, L.Y., Jan, Y.N., Cabrera, C., Buskin, J.N., Hauschka, S.D., Lassar, A.B., et al. 1989b. Interactions between heterologous helix-loop-helix proteins generate complexes that bind specifically to a common DNA sequence. Cell 58: 537-544.

Naya, F.J., Stellrecht, C.M.M., and Tsai, M.J. 1995. Tissue specific regulation of the insulin gene by a novel basic helixloop-helix transcription factor. Genes \& Dev. 9: 1009-1019.

Naya, F.J., Huang, H.P., Qiu, Y., Mutoh, H., DeMayo, F.J., Leiter, A.B., and Tsai, M.J. 1997. Diabetes, defective pancreatic morphogenesis, and abnormal enteroendocrine differentiation in BETA2/NeuroD-deficient mice. Genes \& Dev. 11: 2323-2334.

Olson, E.N. and Klein, W.H. 1994. bHLH factors in muscle development: Dead lines and commitments, what to leave in and what to leave out. Genes \& Dev. 8: 1-8.

Perez, S.E., Rebelo, S., and Anderson, D.J. 1999. Early specification of sensory neuron fate revealed by expression and function of neurogenins in the chick embryo. Development 126: 1715-1728.

Perron, M., Opdecamp, K., Butler, K., Harris, W.A., and Bellefroid, E.J. 1999. X-ngnr-1 and Xath3 promote ectopic expression of sensory neuron markers in the neurula ectoderm and have distinct inducing properties in the retina. Proc. Natl. Acad. Sci. 96: 14996-15001.

Rodriguez, I., Hernandez, R., Modolell, J., and Ruis-Gomez, M. 1990. Competence to develop sensory organs is temporally and spatially regulated in Drosophila epidermal primordia. EMBO J. 9: 3583-3592.

Roztocil, T., Matter, S.L., Alliod, C., Ballivet, M., and Matter, J.M. 1997. NeuroM, a neural helix-loop-helix transcription factor, defines a new transition stage in neurogenesis. Development 124: 3263-3272.

Ruiz-Gomez, M. and Modolell, J. 1987. Deletion analysis of the achaete-scute locus of Drosophila melanogaster. Genes Dev. 1: 1238-1246.

Salo, P.T. and Tattom, W.G. 1993. Age-related loss of knee joint afferents in mice. J. Neurosci. Res. 35: 664-677.

Schwab, M.H., Druffel-Augustin, S., Gass, P., Jung, M., Klugmann, M., Bartholomae, A., Rossner, M.J., and Nave, K.A. 1998. Neuronal basic helix-loop-helix proteins (NEX, NeuroD, NDRF): Spatiotemporal expression and targeted disruption of the NEX gene in transgenic mice. J. Neurosci. 18: $1408-1418$.

Sengupta, P. and Bargman, C. 1996. Cell fate specification in the CNS of C. elegans. Dev. Genet. 18: 73-80.

Sestan, N., Artavanis-Tsakonas, S., and Rakic, P. 1999. Contactdependent inhibition of cortical neurite growth mediated by notch signaling. Science 286: 741-746.

Shimizu, C., Akazawa, C., Nakanishi, S., and Kageyama., R. 1995. MATH-2, a mammalian helix-loop-helix factor structurally related to the product of Drosophila proneural gene atonal, is specifically expressed in the nervous system. Eur. J. Biochem. 229: 239-248.

Skeath, J.B. and Carroll, S.B. 1991. Regulation of achaete-scute gene expression and sensory organ pattern formation in the Drosophila wing. Genes \& Dev. 5: 984-995.

Sommer, L., Ma, Q., and Anderson, D.J. 1996. neurogenins, a novel family of atonal-related bHLH transcription factors, are putative mammalian neuronal determination genes that 
reveal progenitor cell heterogeneity in the developing CNS and PNS. Mol. Cell. Neurosci. 8: 221-241.

Takebayashi, K., Takahashi, S., Yokota, C., Tsuda, H., Nakanishi, S., Asashima, M., and Kageyama, R. 1997. Conversion of ectoderm into a neural fate by ATH-3, a vertebrate basic helix-loop-helix gene homologous to Drosophila proneural gene atonal. EMBO J. 16: 384-395.

Torres, M. and Giraldez, F. 1998. The development of the vertebrate inner ear. Mech. Dev. 71: 5-21.

Van Doren, M., Bailey, A.M., Ensayra, J., Ede, K., and Posakony, J.W. 1994. Negative regulation of proneural gene activity: Hairy is a direct transcriptional repressor of achaete. Genes \& Dev. 8: 2729-2742.

van Staaden, M.J. and Romer, H. 1998. Evolutionary transition from stretch to hearing organs in ancient grasshoppers. $\mathrm{Na}$ ture 394: 773-776.

Vervoort, M., Merritt, D.J., Ghysen, A., and Dambly-Chaudiere, C. 1997. Genetic basis of the formation and identity of type I and type II neurons in Drosophila embryos. Development 124: 2819-2828.

Villares, R. and Cabrera, C.V. 1987. The achaete-scute gene complex of $D$. melanogaster: Conserved domains in a subset of genes required for neurogenesis and their homology to myc. Cell 50: 415-424.

White, N.M. and Jarman, A.P. 2000. Drosophila atonal controls photoreceptor R8-specific properties and modulates both receptor tyrosine kinase and hedgehog signaling. Development 127: $1681-1689$

Yager, D.D. 1999. Structure, development, and evolution of insect auditory systems. Wiley-Liss, New York, NY.

Yan, R.T. and Wang, S.Z. 1998. NeuroD induces photoreceptor cell overproduction in vivo and de novo generation in vitro. I. Neurobiol. 36: 485-496.

Zhao, C. and Emmons, S.W. 1995. A transcription factor controlling development of peripheral sense organs in C. elegans. Nature 373: 74-78.

Zheng, J.L. and Gao, W.Q. 2000. Overexpression of Math1 induces robust production of extra hair cells in postnatal rat hair inner ears. Nat. Neurosci. 3: 580-586.

zur Lage, P. and Jarman, A.P. 1999. Antagonism of EGFR and notch signalling in the reiterative recruitment of Drosophila adult chordotonal sense organ precursors. Development 126: 3149-3157. 


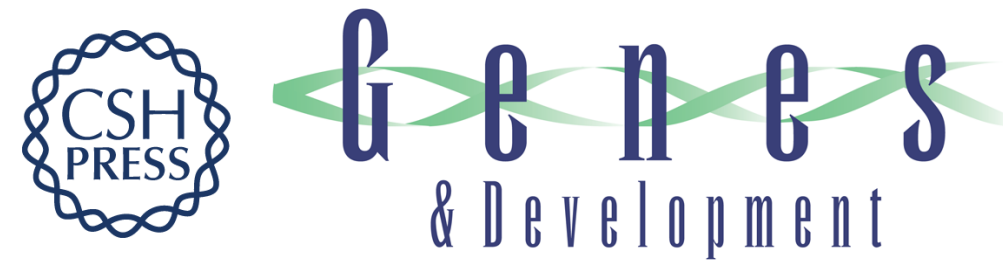

\section{Doing the MATH: is the mouse a good model for fly development?}

Bassem A. Hassan and Hugo J. Bellen

Genes Dev. 2000, 14:

Access the most recent version at doi:10.1101/gad.14.15.1852

References This article cites 124 articles, 51 of which can be accessed free at: http://genesdev.cshlp.org/content/14/15/1852.full.html\#ref-list-1

License

Email Alerting Receive free email alerts when new articles cite this article - sign up in the box at the top Service right corner of the article or click here.

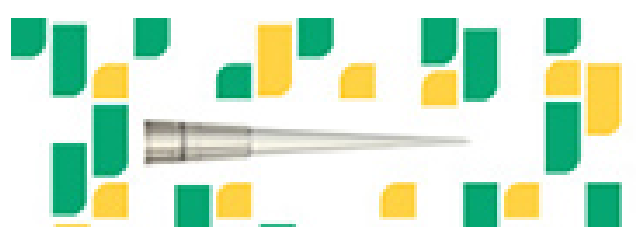

Focused on your science. 